\title{
Investigating the Relationship between Attachment Styles and the Manner of Mobile Phone Usage among Iranian Students
}

\author{
Hoseini Shadi*, Toozandehjani Hassan\# \\ Department of Psychology, Faculty of Humanities, Neyshabur Branch, Islamic Azad University, Neyshabur, Iran \\ Email: dy.hoseyni@gmail.com, H.Toozandehjani@ymail.com
}

How to cite this paper: Shadi, H. and Hassan, T. (2017) Investigating the Relationship between Attachment Styles and the Manner of Mobile Phone Usage among Iranian Students. Social Networking, 6, 206-214.

https://doi.org/10.4236/sn.2017.62013

Received: November 25, 2016

Accepted: April 27, 2017

Published: April 30, 2017

Copyright ( 92017 by authors and Scientific Research Publishing Inc. This work is licensed under the Creative Commons Attribution International License (CC BY 4.0). http://creativecommons.org/licenses/by/4.0/

\begin{abstract}
The present study is an applied research in terms of purpose and a descriptive and correlational research in terms of the method of data collection, which has been conducted to examine the relationship between attachment styles and the manner of using the mobile phone. The statistical population of this study comprised male and female students studying at the undergraduate level of Islamic Azad Unidersity of Neyshabur (Department of Humanities) in the academic year 2013-2014. The statistical sample included 300 individuals from these students who were selected through stratified random sampling. Hazan and Shaver's Adult Attachment Questionnaire (AAQ) and a researcher-made Mobile Phone Questionnaire was used to collect the data. The results indicated that there was a significant relationship between the manner of using mobile phone and its dimensions with attachment styles.
\end{abstract}

\section{Keywords}

Attachment Styles, Mobile Phone

\section{Introduction}

One of the unique features of today's world is the existence of extensive human communications [1]. Today, new communication technologies have become widespread and have changed the world. In our time, the role of technology in individual, social and human life has increased. Studies have shown that technology has been the most powerful factor of change in societies and its development is a continuous process [2]. One of the issues to which a major part of the activities of psychologists and sociologists has been allocated is the impact of

${ }^{\star}$ B.A. in General Psychology.

\#Assistant Professor of Psychology. 
technology on society and people's life [3]. Mobile phone as one of the most important technological artifacts has turned into an integral part of everyday life in modern times. Mobile phone that was once a symbol of economic position and class has now assumed numerous roles and applications, often in a contradictory manner, in individual, cultural and social levels. It should be acknowledged that today, mobile phone is the most important individual technology which, while creating independent individual privacy, has made the individual's social relationship meaningful in the context of an individualized network [4].

Mobile phone like many of the new technologies gives individuals or social groups more power by providing them with further and more diverse options. But in all these cases, increased freedom enhances autonomy, social responsibility and social control [5]. Hence, this technology has changed the lifestyles of young people more than the lifestyles of other traditional groups [6]. Youths and adolescents use mobile phone to maintain their social networks and form new relationships. Mobile phone has become an important tool which young people use to determine their personal space [7]. Thus, analysis of the changes resulting from embedding new media in everyday life and exploration of the relationship between such technology with the concept of identity and lifestyle of young people are the main issue of our time. Today, with the growth of the knowledge of psychology, we know that human personality has multiple dimensions. Additionally, by taking advantage of the knowledge of sociology, it has become clear that people in the present age play numerous and complex roles. According to Goffman, in different situations of everyday life, we sometimes feel ourselves differently and play one or several different roles and consequently reveal one or more aspects of our personality [8]. Expression generally occurs through various tools and devices. This means that to reflect our characteristics in the social level, we use the tools which have common meanings and also have a specific sense in the inter-mental space of different individuals in a group or community [9].

In a qualitative study, [10] examined the socialization process of mobile phone in everyday life. This research indicates that the use of mobile phone is a personal matter which is strongly affected by social factors and processes. Permanent availability imposes telephone harassment, troubles and many unwanted programs on the individual. On the other hand, turning off the mobile phone can be a source of tiredness, waiting or mental stress of the person demanding for making contact and may somehow weaken the individual's efficiency. In a study conducted by [11] regarding the application of information and communication technology in today's world, the findings showed that information and communication technology and use of mobile phone have led to reduced social relations. [12] carried out a study entitled "The impact of mobile phone on the social life of young people". He tried to investigate the effect of mobile phone on the relationships of young peers, family and school. The results and studies conducted revealed that the mobile phone leads to organizing and maintaining the social networks of youths and also has negative effects on the relationships of young peers, including rejection. Further, the findings suggested that the mobile 
phone results in change in family dynamics, too much reliance on mobile phone and disorder in studying. In a research entitled "The relationship between mobile phone use with uncertainty in relationship, love, commitment and attachment styles", [13] examined the influence of mobile communications on romantic relationships. Based on the findings, greater use of mobile phone in relation to a romantic partner has a lower relationship with uncertainty and has a high relationship with commitment. Also, avoidance and anxiety are related to the use of mobile voice calls. However, there are no significant results regarding the use of text messages. Generally, most of the contacts with the mobile phone can be seen in romantic relationships.

Concerning the attachment styles, it can be said that attachment is a psychological term that states the child's socio-emotional relationship with the mother. Attachment includes a deep and sustainable biological, psychological and social situation that is formed on the basis of the relationship between the child and his care givers in the early years of life. This psychological phenomenon is considered as one of the major factors in the social and emotional development of children. Attachment plays an important role in the formation of identity and personality of individuals [14]. By offering the attachment theory, Bowlby intended to determine the mechanisms that lead to the establishment of a relationship between attachment and other dimensions of the psychosocial change. Bowlby considers the attachment theory as a goal-corrected control system which creates a kind of intrapersonal psychological organization [15]. In other words, initial interactions with the attachment figure are encoded as psychological representations (positive and negative patterns of self and others). These patterns affect the child's behaviors and expectations in the interpersonal relationships during the life span [16]. Many of the research findings have referred to the role of attachment quality in the formation of identity [10] [11] [12].

The study conducted by [17] entitled "Investigating the mediating role of SMS in the relationship between attachment style and perceived social support" revealed that attachment styles have no significant relationship with perceived social support and also the motivation of using SMS and its content. Secure people send more text messages compared to insecure people. Regarding the motivation of using SMS, it was found that there is a significant positive relationship between the factor of avoidance of anxiety in face to face relationships and perceived social support from friends. On the other hand, a significant direct relationship exists between the factor of conventional orientation and perceived social support from family. As regards the content of text messages, the results indicate that the unconventional factor and perceived social support from family have an inverse relationship. [18] carried out a research entitled "Examining the relationship between attachment, style of coping with life stress and the manner of responsiveness". The results suggested that attachment security is positively related to family relations and is negatively associated with the negative avoidance behavior such as running away from home, begging and drug abuse. [19] demonstrated that attachment styles have a relationship with the rate of home- 
sickness, depression and emotional stability and adaptive behavior of children. People with insecure attachment have a greater sense of homesickness and loneliness, more depression and less emotional stability and adaptive behavior [12].

Since attachment styles play one of the most fundamental roles in the individual's attitude towards himself and relationship of people with each other and are also one of the effective factors in relationships and acquisition of identity, identification of attachment styles and related problems is among the important and essential issues, particularly with regard to the cultural-social context of society. Besides, individual and social consequences of developing mobile phone use among youths are the issue that has not been much investigated by experts, scholars and researchers of Human Sciences despite its importance. Accordingly, the aim of the present study is to arrive at a proper answer to the question as to whether there is a significant relationship between attachment styles and the manner of mobile phone use.

\section{Research Methodology}

In terms of purpose, the present study is an applied research and in terms of the method of data collection, it is a descriptive and correlational study. The statistical population of the research comprised male and female students studying at the undergraduate level of Neyshabur Islamic Azad University (Department of Humanities) in the academic year 2013-2014. The statistical sample included 300 students of this population, who were selected through stratified random sampling.

\section{Research Tools}

Hazan and Shaver's Adult Attachment Questionnaire (AAQ): To measure the attachment styles, Adult Attachment Scale is used. This scale, which has been made using the materials of Hazan and Shaver attachment test and has been standardized for the students of Tehran University, is a 15-item test and measures three secure, avoidant and ambivalent attachment styles on a 5-point Likert scale (1-very low, 2-low, 3-medium, 4-high and 5-very high). Items exist as secure style, avoidant style and ambivalent style. Alpha coefficients of (reliability) questions about the subscales of secure, avoidant and ambivalent attachment styles regarding a student sample ( 1480 people) were calculated to be respectively $0.86,0.84$ and 0.85 for all the subjects, which indicate good internal consistency of Adult Attachment Scale. Kendall's concordance coefficients (validity) for secure, avoidant and ambivalent attachment styles were obtained respectively $0.80,0.61$ and 0.75 .

Researcher-made Mobile Phone Questionnaire: This questionnaire has been analyzed and prepared based on internal and external records. After setting the initial questionnaire, a pilot experiment was conducted to assess its validity and reliability. After making necessary modifications, the questionnaire was completed by the students under the supervision of the researcher and questioners, which included open and closed questions and in most of the questions, a 5-point Likert scale was used for measurement. Construct validity was achieved 
by performing factor analysis for the constructs used in this study. Factor analysis for the variable, i.e. the use of mobile phone, with Kmo index is equal to 0.798 which indicates the construct validity of the amount of mobile phone use.

The research main hypothesis suggested that "there is a significant relationship between attachment styles and the manner of mobile phone use among users". To investigate this hypothesis, Pearson correlation test was employed and the summary of obtained results has been provided in Table 1.

As can be seen in Table 2, the index of perceived adjustment has a significant relationship only with avoidant attachment and this relationship in inverse. Further, there is a significant direct relationship between the index of perceived usefulness and secure attachment style. Also, a significant relationship exists between this index and avoidant attachment style, which is inverse with regard

Table 1. Cronbach's alpha test to assess the reliability of the indicators of mobile phone use.

\begin{tabular}{cc}
\hline Index & Cronbach's alpha coefficient \\
\hline Perceived adjustment (perceived behavioral control) & 0.716 \\
Perceived usefulness (self-efficacy of technology) & 0.685 \\
Perceived ease of use & 0.747 \\
Perceived enjoyment (technological innovation) & 0.753 \\
Perceived social influence (subjective norm) & 0.759 \\
Perceived confidence & 0.712 \\
Perceived image & 0.723 \\
\hline
\end{tabular}

Table 2. Studying the relationship between attachment styles and the manner (reasons) of using mobile phone.

\begin{tabular}{|c|c|c|c|c|}
\hline & & $\begin{array}{c}\text { Secure } \\
\text { attachment }\end{array}$ & $\begin{array}{l}\text { Ambivalent } \\
\text { attachment }\end{array}$ & $\begin{array}{l}\text { Avoidant } \\
\text { attachment }\end{array}$ \\
\hline \multirow{2}{*}{ Perceived adjustment } & Correlation coefficient & 0.082 & 0.062 & $-0.129^{*}$ \\
\hline & Significance level & 0.156 & 0.289 & 0.026 \\
\hline \multirow{2}{*}{ Perceived usefulness } & Correlation coefficient & $0.127^{\star}$ & 0.014 & $-0.117^{\star}$ \\
\hline & Significance level & 0.028 & 0.811 & 0.043 \\
\hline \multirow{2}{*}{ Perceived ease of use } & Correlation coefficient & $0.162^{* *}$ & -0.066 & $-0.164^{\star *}$ \\
\hline & Significance level & 0.005 & 0.257 & 0.005 \\
\hline \multirow{2}{*}{ Perceived enjoyment } & Correlation coefficient & $0.216^{* *}$ & $0.187^{\star \star}$ & -0.101 \\
\hline & Significance level & 0.000 & 0.001 & 0.081 \\
\hline \multirow{2}{*}{ Perceived social influence } & Correlation coefficient & $0.176^{\star \star}$ & -0.075 & $-0.119^{*}$ \\
\hline & Significance level & 0.002 & 0.195 & 0.04 \\
\hline \multirow{2}{*}{ Perceived confidence } & Correlation coefficient & 0.091 & $-0.184^{* *}$ & -0.04 \\
\hline & Significance level & 0.116 & 0.001 & 0.491 \\
\hline \multirow{2}{*}{ Perceived image } & Correlation coefficient & -0.038 & -0.018 & -0.057 \\
\hline & Significance level & 0.513 & 0.763 & 0.328 \\
\hline
\end{tabular}


to negativity of the correlation coefficient. Additionally, there is a significant direct relationship between the index of perceived ease of use and secure attachment style and also a significant inverse relationship between perceived ease of use and ambivalent attachment style. The index of perceived enjoyment has a significant direct relationship with secure and ambivalent attachment styles and no significant relationship with avoidant attachment style. Moreover, social influence has a significant direct relationship with secure attachment style and a significant inverse relationship with avoidant attachment style, but this index has no significant relationship with ambivalent attachment style. The index of perceived confidence is significantly related only to ambivalent attachment style and has no significant relationship with other two styles. And finally, no significant relationship was found between the index of perceived image and attachment styles.

\section{Discussion and Conclusion}

Mobile phone is considered as a means of communication whose developing capacities have turned this communication tool into a computer and multimedia capacity. From this perspective, mobile phone is regarded as a kind of individual technology which reflects a new scope of independence of individualism [10]. Although the expansion of this phenomenon gives a sense of independence to the individual and releases him from some social commitments, it has adverse social consequences on a large scale. Studies conducted in connection with attachment styles have expressed the importance of this variable such that attachment lays the foundation of healthy emotional and social development in adulthood and affects the successful formation of identity that is associated with mental health. Many studies have shown that individuals' attachment pattern is a reliable predictor to explain their differences in psychological dimensions, social dependencies, social cognition, romantic and sexual relationships, levels of stress and emotional control, reaction to separation, efficiency in interpersonal relationships and individuals' schema toward self and others. For instance, disorganized attachments are associated with severe disorders, depression, antisocial behaviors and adjustment problems and difficulty in proper parenting [5] [6].

By the same token and given the importance of the role of youths in society and increasing development of technology particularly the existence of mobile phones, the present study intends to investigate the relationship between attachment styles and the manner of mobile phone use among the students of Neyshabur Azad University. The results obtained from hypothesis testing indicating the existence of "a relationship between attachment styles and the manner of mobile phone use" demonstrated that the index of perceived adjustment had a significant relationship only with avoidant attachment and this relationship in inverse. Further, there is a significant direct relationship between the index of perceived usefulness and secure attachment style. Also, a significant inverse relationship exists between this index and avoidant attachment style. Additionally, 
there is a significant direct relationship between the index of perceived ease of use and secure attachment style and a significant inverse relationship between perceived ease of use and ambivalent attachment style. The index of perceived enjoyment has a significant direct relationship with secure and ambivalent attachment styles and no significant relationship with avoidant attachment style. Moreover, social influence has a significant direct relationship with secure attachment style and a significant inverse relationship with avoidant attachment style, but this index has no significant relationship with ambivalent attachment style. The index of perceived confidence is significantly related only to ambivalent attachment style and has no significant relationship with other two styles. And finally, no significant relationship was found between the index of perceived image and attachment styles.

These results are consistent with many of the findings. For example, we can refer to the studies by Ainsworth, which revealed that attachment helps to reduce anxiety. [3] [4] concluded from their numerous studies that the quality of attachment to parents and peers is related to mental health of adolescents, identity formation, coping with various crises and life satisfaction [18]. [12] found that students use the ancillary facilities of mobile phones to fill their leisure time and communicate with friends. Results of Pearson correlation coefficient showed that there is a relationship between attachment to mobile phone with increased unhealthy relationships and academic failure (using mobile phone leads to academic failure in students and also reduced emotional relationship of adolescents with their families). [11] in her study came to the conclusion that a significant positive relationship exists between impulsivity and feeling of loneliness with the amount of mobile phone use. Besides, results of regression analysis indicated that among the predictor variables, only impulsivity can predict the amount of mobile phone use. [4] revealed that a kind of intergenerational digital gap is growing in our society that exacerbates the psychosocial distance between parents and adolescents and youths. The results related to the deterrent effect of religious upbringing on abnormal use of mobile phone have shown the effectiveness of internal control in the prevention of deviations. In another research, [5] reported that harmful use of mobile phone has a significant positive relationship with neuroticism and a significant negative relationship with extroversion. Other findings suggested that there is a significance difference between male and female and married and single students in terms of mobile phone use, meaning that mobile phone use in girl students and also single students is more than boy students and married students. [7] argued that there is a significant relationship between parent attachment styles and personality traits (with the exception of extraversion and openness) with dependence on mobile phone. Further, maternal insecure attachment style and neuroticism are the predictor of their vulnerability to dependence on mobile phone. Unlike the results of this research which indicate the greater use of mobile phone among male students relative to female students, the findings achieved by [8] demonstrated that the amount of mobile phone use is higher among female students compared to male 
students. Moreover, [9] in her study concluded that there are significant gender differences among students in terms of motivation and use of mobile phone facilities. But no significant relationship was observed between gender and the amount of mobile phone use. [18] showed that attachment security is positively related to family relations, but has a negative relationship with negative avoidance behavior, including running away from home, begging and drug abuse.

Man is a social being who communicates with the surrounding environment to meet his various needs. Sometimes, obstacles and difficulties arise in human life, which disturb the adjustment and consequently mental balance of individuals. As a result, people become entangled in stress and discomfort which may lead to the incidence of mental disorders. This preparation for disorder causes the occurrence of specific behaviors in the individual who seeks a solution for peace. People show different behaviors from the general population in various ways. One of these ways in which the individual seeks to resolve his personal problems is the use of mobile phone [1].

From the cognitive perspective, it is believed that the person's inability in the formation of schemas and appropriate cognitions leads to mental disorders [7]. In a study, it was found that obsessive-compulsive disorder, pornography and abuse are among the common instances in the use of mobile phones [6]. [14] in his study refers to reduced emotions, text-accepting, identity flexibility and alternative communications, cocoon formation and reaching peace and tranquility in the use of mobile phone.

Users of the mobile phone, due to anonymity, engage in self-disclosure and pave the way for the establishment of communication in the virtual environment to form intimate relationships for the expression of what they cannot state in real world. Youths and adolescents seek to communicate because of their social, emotional and sexual needs and mobile phone can provide this opportunity to fill the emotional vacuum of these individuals. Due to easy access to the mobile phone, diversity in communications, no need for investment and considering the fact that the person is not recognized and his real identity remains hidden and that this environment has low risk, the tendency to use the mobile phone is increasingly seen among adolescents and young people [19].

Many factors lead to improper use of the mobile phone and one of its reasons is the psychological aspect of the issue. Most of the people who are mentally depressed and are in a state of distress become addicted to the use of mobile phones more than others. Escape from reality and the real world and easy communication via mobile phone have turned this tool into a facility for the exchange of thoughts among the young people of society. However, attractions of communications through mobile phone cannot be denied. But it should also be remembered that the virtual environment is a space that, while having threats and limitations, can be accompanied by many opportunities and capabilities [5].

\section{References}

[1] Panahi, Y. (2011) Dependence on Mobile Phone and Psychosocial Traumas in Stu- 
dents: Investigating the Effects of SMS and Bluetooth. Counseling Center of the Department of Education in Ardebil, Ardebil.

[2] Baqeri, Kh. (2009) Relationship between Attachment Styles and Type of Identity among 15 - 30-Year-Old Prisoners. Journal of Applied Psychology, 3, 85-99.

[3] Dehqan, A. and Nikbakhsh, B. (2006) Study of People's Behavior in the Virtual Environment: Formation of Intimate Relationships in Internet Chat Rooms. Journal of Cultural Studies and Communications, 6, 20-31.

[4] Zokaei, S. (2004) Youths and Virtual Leisure. Journal of Youth Studies, 6, 85-92.

[5] Rosenhan, D. and Seligman, M. (2011) Abnormal Psychology. Seyyed Mohammadi, Y., Trans., Tehran University, Tehran.

[6] Gorgi, A. (2006) Internet and Identity. Journal of National Studies, 7, 54-63.

[7] Amoli, S. (2006) New Individualism and Mobile Phone: Technology of Individualism and Identity. Internet Magazine of Global Media, 7, 120-134.

[8] Mir Mohammad Sadeqi, M. (2012) Examining the Position and Effectiveness of the Class of "Network Leaders" in Online Social Network of Facebook. Journal of Interdisciplinary Studies in Media and Culture. Research Institute of Humanities and Cultural Studies, 2, 13-18.

[9] Ahmadi, S., Mehdizadeh, M. and Aqili, V. (2009) The Impact of Mobile Phone Use on the Formation of Modern Personal Identity in Adolescents and Youths of Tehran. Journal of Communication Research, 16, 4-125.

[10] Haqshenas, F. (2010) Investigating the Relationship between Impulsivity and Feeling of Loneliness with the Amount of Mobile Phone Use among Students. New Findings in Psychology, 2, 87-94.

[11] Charoudeh, H. (2010) Examining the Amount and Causes of Using Mobile Phone by Students. Report of the Research Project of Jahad Daneshgahi of Ferdowsi University.

[12] Delavar, A. (2006) Probabilities and Applied Statistics in Psychology and Educational Sciences. Roshd Publishing, Tehran.

[13] Shahyad, Sh. (2009) The Mediating Role of SMS in the Relationship between Attachment and Perceived Social Support. Master's Thesis, Psychology, Shahid Beheshti University, Tehran.

[14] Amoli, S. (2006) New Individualism and Mobile Phone: Technology of Individualism and Identity. Global Media Journal of Tehran University, 1, 92-99.

[15] Abedini, Y. (2012) Investigating the Motivation, Amount and Type of Mobile Phone Use in Students. Journal of Contemporary Psychology, 2, 73-86.

[16] Keyvankar, M. (2013) Perceived Attachment of Childhood and Personality Traits in the Pattern of Dependence on Mobile Phone. Developmental Psychology Journal of Iranian Psychologists, 9, 61-72.

[17] Kalantari, A. and Hasani, H. (2011) New Media and Daily Life: The Impact of Mobile Phone on Identity and Lifestyle of Youths. Journal of Media, 19, 75-83.

[18] Negahban Salami, M. and Hejazi, E. (2009) Relationship between Styles of Attachment to Parents and Peers with Identity Styles in Adolescents. Journal of Psychology and Educational Sciences, 39, 107-131.

[19] Yaseminezhad, P. and GolMohammadian, M. (2011) Studying the Relationship between Five Strong Factors of Personality and Harmful Use of Mobile Phone among the Students of Dezfoul Islamic Azad University. Social Psychology Research, 1, $17-24$. 
Submit or recommend next manuscript to SCIRP and we will provide best service for you:

Accepting pre-submission inquiries through Email, Facebook, LinkedIn, Twitter, etc. A wide selection of journals (inclusive of 9 subjects, more than 200 journals)

Providing 24-hour high-quality service

User-friendly online submission system

Fair and swift peer-review system

Efficient typesetting and proofreading procedure

Display of the result of downloads and visits, as well as the number of cited articles Maximum dissemination of your research work

Submit your manuscript at: http://papersubmission.scirp.org/

Or contact $\underline{\text { sn@scirp.org }}$ 